\title{
Tráfico de animais: o que dizem alunos do ensino médio?
}

Animal trafficking: what they say high school students?

\author{
Lucas Loram Lourenço ${ }^{1}$ \\ José Firmino de Oliveira Neto ${ }^{2}$ \\ Camila Aline Romano ${ }^{3}$ \\ Ueslene Maria Ferreira Pontes ${ }^{4}$
}

\section{Resumo}

Tráfico de animais é todo comércio ilegal de espécies nativas de uma determinada região que faz parte da fauna silvestre. Muitas vezes este fato passa despercebido pela sociedade. Neste sentido, o presente trabalho teve como objetivo compreender as concepções de alunos do Ensino Médio sobre o tráfico de animais silvestres, considerando a escola como um espaço de disseminação de saberes, entendendo que a mesma deve atuar discutindo questões como esta, de modo a levar o alunado a uma visão crítica e reflexiva acerca do assunto. A pesquisa se caracteriza como qualitativa, e mediante seu objetivo, como estudo de caso. O objeto de coleta de dados foi o questionário semiestruturado, aplicado a alunos da $3^{\circ}$ série do Ensino Médio de uma escola da rede pública da cidade de Montes Claros de Goiás - GO. Participaram da pesquisa58 alunos, sendo que 91,37\% afirmaram ter ouvido falar sobre tráfico de animais, e 8,63\% arguiram não ter conhecimento sobre o assunto. Os primeiros apontaram que a temática Ihes foi apresentada via jornais, revistas, televisão e internet, respalda-se neste ponto que a escola não foi mencionada. Quanto à percepção dos mesmos sobre o que vem a ser o tráfico de animais, o alunado em maioria (97\%) aponta que o mesmo é uma "maneira cruel de maus tratos aos animais silvestres", fazendo menção a retirada desses seres do seu habitat natural. Citaram também a manutenção do animal em cativeiro onde os mesmos são privados de liberdade. Alguns alunos relataram ainda que, já viram muitas pessoas criando animais silvestres e 3\% já tiveram ou ainda têm animais silvestres como animal de estimação. O último fator pode ser justificado pelo grande contato destes alunos com o ambiente rural, já que a economia da cidade é baseada principalmente em atividades agropastoris, com muitos discentes vivendo no campo e tendo contato direto com a fauna silvestre. Diante dos resultados alcançados pelo questionário, conclui-se que o grupo pesquisado compreende o que vem a ser o tráfico de animais. Contudo, foi possível notar que, mesmo conhecendo a ilegalidade e também as injúrias causadas pelo tráfico, ainda existe uma parcela de alunos que mantêm animais silvestres em cativeiro. Para tanto, ressalta-se a necessidade de que a escola volte seu olhar para a temática, a fim de sensibilizar a população sobre a importância de se evitar condutas que fomentem o tráfico de animais.

\footnotetext{
${ }^{1}$ Instituto Federal Goiano, Campus Rio Verde | lucas.loram@outlook.com

${ }^{2}$ Universidade Federal de Goiás | neto.09@hotmail.com

${ }^{3}$ Universidade Federal de Goiás | k.mila.xf@hotmail.com

${ }^{4}$ Universidade Federal de Goiás | ueslene.pontes@ueg.br
} 
Palavras chave: tráfico de animais; ensino de biologia; percepções discentes.

\section{Abstract}

Animal trafficking is the illegal trade of all species native to a region that is part of the wildlife. This fact often goes unnoticed by society. In this sense, the present study aimed to point out the concepts of high school students about wildlife trafficking, considering that the school is a space for the dissemination of knowledge, must act discussing issues like this in order to bring the student body to a critical and reflective about the vision of the subject. The research is characterized as qualitative, and upon your goal, as a case study. The object of data collection was semi-structured questionnaire administered to students in third year high school students in a school of public schools in the city of Montes Claros de Goiás - GO (16 ${ }^{\circ} 00^{\prime} 26^{\prime \prime S} 51^{\circ} 23$ '52 "O). Participated in the survey a total of 58 students, of which $91.37 \%$ said they had heard about the pet trade, and only a minority of $8.63 \%$ said they had no knowledge on the subject. The first indicated that the topic was presented to them via newspapers, magazines, television and the Internet, backs up this point that the school was not mentioned Regarding their perception about what comes to animal trafficking, the student body at most (97\%) suggests that it is a "cruel manner of mistreatment of wild animals", mentioning the removal of these beings from their natural habitat. Also cited the maintenance of the animal in captivity where they are deprived of liberty. Some students reported that many people have seen creating wildlife. Yet others (3\%) claimed that they have had or still have wild animals as pets. The last factor can be explained by the large contact these students with the rural environment as the city's economy is based primarily on agro-pastoral activities, with many students living in the countryside and having direct contact with wildlife. Given the results achieved by the questionnaire, it was concluded that the studied group understands what comes to animal trafficking. However, it was noticeable that even knowing the illegality and also the injuries caused by traffic, there is still a portion of students who keep wild animals in captivity. At this point, we emphasize the need for the school turns his sights on the topic in order to raise awareness about the importance of avoiding behaviors that promote animal trafficking.

Keywords: trade in animals; biology teaching; student perceptions.

\section{Introdução}

Os animais silvestres são todos os seres vivos que apresentam desenvolvimento, em qualquer fase do seu ciclo de vida, fora do cativeiro (BRASIL, 1967), onde não há a intervenção humana, desempenhando seu papel ecológico no ecossistema ao qual pertence. Alguns exemplos de animais silvestres característicos da fauna brasileira são: a arara azul grande, lobo guará, o cachorro-vinagre e a ararinha azul, já considerada extinta em ambiente natural (BRASIL, 2003). Esses animais, bem como produtos obtidos por meio destes, são de propriedade da União, sendo vetada por vias legais toda a apreensão e/ou comercialização dos mesmos(BRASIL, 1967). Dessa forma, perseguir, matar, destruir ninhos ou outros abrigos de animais silvestres, bem comercializá-los, dentre outras atividades que impeçam o ciclo natural das espécies, conforme o artigo 29 da Lei Federal 9.605 é crime com pena de seis meses a um ano de reclusão e multa (BRASIL, 1996). 
Muitos dos animais que fazem parte da fauna silvestre vêm sofrendo com a ação antrópica, sendo uma delas, o tráfico de animais. Caracteriza-se tráfico de animais, como todo comércio ilegal de espécies que fazem parte da fauna silvestre. Este é o terceiro maior tipo de tráfico do mundo, perdendo apenas para o de armas e drogas. Este tipo de comércio é ainda maior quando envolve espécies raras, já que, em virtude da baixa abundância de indivíduos, agrega-se maior valor comercial a espécime, incentivando ainda mais a ação predatória (RENCTAS, 2001). Além disso, o tráfico de animais silvestres está entre os principais fatores que levam uma espécie ao risco de extinção (BRANCO; RIBEIRO, 2011).

No Brasil, desde o seu descobrimento em 1500, os recursos naturais são explorados e levados ao exterior pelo comércio ilegal de animais silvestres. As primeiras notícias sobre a retirada de animais silvestres das matas brasileiras com destino ao exterior provem do descobrimento, primeiramente pelos portugueses e depois por franceses e holandeses (SAAB, 2006). Os animais eram levados da colônia à corte especialmente devido ao fascínio que as plumagens e peles exerciam na época, sendo considerados como acessórios de luxo com alto valor comercial (SICK, 1988). Somente a partir de 1967 foi criada uma lei para proteção da fauna, a Lei de no 5.197. Assim, qualquer atividade de animais silvestre sem registro passou a ser considerada ilegal. A referida Lei foi atualizada em 12 de fevereiro de 1998, Lei nº. 9.605 - Leis de Crimes Ambientais (DAL'AVA, 2003).

Animais silvestres que são retirados da natureza acabam sofrendo com a presença do homem, com os maus tratos, gaiolas e a diferença de seu habitat natural com o novo ambiente que é obrigado a viver. Por este motivo, apresentam em condições de cativeiro, dificuldades para se alimentar, crescer e se reproduzir, muitos chegam a óbito por doenças e estresse. Grande parte desses animais que são capturados para o tráfico, são levados para o exterior, onde possuem maior valor comercial (RENCTAS,2001).Na tentativa de transportar esses animais para fora do país, alguns espécimes são por vez apreendidos por profissionais do Instituto Brasileiro do Meio Ambiente e dos Recursos Naturais Renováveis (IBAMA). Os animais apreendidos nestas circunstâncias são tratados e inseridos no processo de reabilitação e reintrodução a natureza. Contudo, parte dos animais apreendidos não possui condições para retornar a seu habitat natural. Nesse caso, os animais são direcionados para zoológicos ou instituições de reabilitação para animais que sofrem maus tratos, onde recebem tratamento diferenciado (RENCTAS, 2001).

Considerando a importância de sensibilizar a sociedade sobre as ações ilegais no que concerne ao tráfico de animais silvestres, o presente trabalho se propõe a compreender as concepções de alunos de Ensino Médio de uma escola da rede pública de Montes Claros de Goiás-GO acerca da temática. Para tanto, antes serão elencados alguns pontos importantes nos que diz respeito ao tráfico de animais, bem como do papel da Escola e da Educação Ambiental. Após o levantamento dos dados far-se-á uma conscientização do papel dos cidadãos brasileiros quanto à preservação da fauna e flora.

\section{Aproximações: tráfico de animais e educação escolar}

A educação é fundamental para o desenvolvimento do indivíduo, a globalização exige domínio sobre várias questões, como as tecnologias, o que demanda informação e conhecimento para manuseio das distintas e variadas ferramentas disponíveis ao homem no momento. Assim, espera-se da escola uma gama de questões para o desenvolvimento e afirmação do indivíduo perante a sociedade, nesse viés a Educação está atrelada a uma 
interface neoliberal (GIRON, 2008), onde o conhecimento técnico é explorado em detrimento do saber criticamente construído. Nesse sentido, aponta-se a necessidade de práticas transgressoras, ou seja, que caminhem para além da lógica pautada no capital e realmente emancipe criticamente o sujeito, possibilitando ao mesmo desvelar as nuances que thes são impostas e viver uma vida de plenitude. Com essas considerações iniciais é que se respalda a relevância da disciplina escolar Biologia, evidenciando a educação científica.

A Biologia no Ensino Médio é fundamental. O mundo está em constante transformação, e essas mudanças rondam em torno das ciências e tecnologias que estão ao nosso redor para facilitar a vida dos seres humanos (MALAFAIA; BARBARO; RODRIGUES, 2010). Segundo Krasilchik (2004), estudar biologia no Ensino Médio tem uma grande importância para os seres humanos, pois uma de suas funções é abrir a mente e os olhos dos cidadãos, para que estes sejam capazes de compreender e se atualizarem acerca de temáticas ligadas a ciência, biologia e as novas tecnologias.

Ao ensinar Biologia nas escolas, entende-se que se deve efetivar íntima relação com as questões ambientais (TRAVASSOS, 2001), haja vista ser a Educação Ambiental (EA)"um processo educativo que objetiva a instrumentalização dos sujeitos para o enfrentamento das causas da crise sócio-ambiental, visando à emancipação das condições determinadas pelo modo de produção capitalista" (TEIXEIRA; AGUDO; TALAMONI, 2015).

Faz-se salientar que a EA que se aborda neste texto é de cunho crítico, em detrimento de uma concepção conservadora e ou pragmática da mesma (TRIVELATO; SILVA, 2011). "Entendemos a pertinência da escolha por uma concepção crítica, que privilegia a dimensão política da questão ambiental e questiona o modelo econômico vigente" (idem, p. 20). Assim, Trivelato e Silva (2011, p. 20-21), por meio das colocações de Loureiro (2006), colocam que não cabe nesta perspectiva crítica: 1) discutir conservação sem considerar os processos sociais que levaram ao atual quadro de esgotamento e extinção; 2) falar em mudanças de comportamentos sem pensar como cada indivíduo vive, seu contexto e suas possibilidades concretas de fazer escolhas; 3) defender uma forma de pensar a natureza, ignorando como cada civilização, cada sociedade e cada comunidade interagiam nela e definiam representações sobre ela; 4) como produziam, geravam cultura e estilos de vida e como isso se dá hoje.

Neste trabalho, como já referendado, discute-se sobreo problema ambiental do tráfico de animais silvestres no contexto escolar, investigando as percepções de alunos do Ensino Médio. Para tanto, coloca-se que alinhavado a perspectiva crítica que se defende,

[...] no âmbito das escolas é preciso que fique definido como objetivo pedagógico, qual tipo de educação ambiental deve ser seguido, uma educação conservacionista que é aquela cujos ensinamentos conduzem ao uso racional dos recursos naturais e à manutenção de um nível ótimo de produtividade dos ecossistemas naturais ou gerenciados pelo homem, ou uma educação voltada para o meio ambiente que implica em uma profunda mudança de valores, em uma nova visão de mundo, o que ultrapassa bastante o estado conservacionista (TRAVASSOS, 2001 p. 2).

Segundo Quintão, Sabino e Sabino (2011), é de grande interesse que nas aulas de Biologia, que o professor trabalhe e discuta com os alunos sobre ações ecológicas onde há interferência do tráfico de animais. Este tema está tanto associado com a sensibilização dos alunos sobre as relações ecológicas e biodiversidade, como com o cotidiano da sociedade, 
muitas vezes explorado por distintos exames, tal qual o Exame Nacional do Ensino Médio (ENEM).

\section{Metodologia}

\section{Área de estudo}

A pesquisa foi realizada na cidade de Montes Claros de Goiás (Figura 1), a qual dista da capital do estado, Goiânia, 291 km, no Colégio Estadual Francisco Modesto da Silva. O colégio atende alunos de Ensino Fundamental e Ensino Médio.

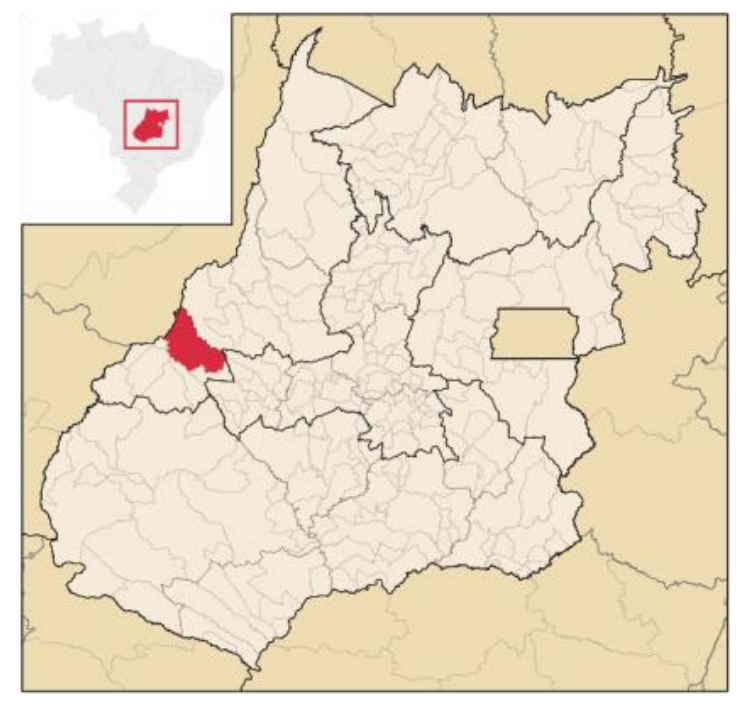

Figura 1. Localização do Município de Montes Claros de Goiás, GO Fonte: http://pt.wikipedia.org (ABREU, 2006).

A pesquisa foi desenvolvida com alunos da $3^{\circ}$ série do Ensino Médio do colégio.A escolha deste grupo se deu mediante dois fatores: 1)por os mesmos estarem findando o ensino médio, estes devem possuir um conhecimento sistematizado acerca de temática básica, no caso deste trabalho do tráfico de animais, 2) por estarem na $3^{\circ}$ série e entendermos que boa parte irá realizar o vestibular, devem estar cientes de discussões sociais, conseguindo apresentar juízo de valor a inúmeras consequências das atitudes humanas, já que temáticas que exigem este nível de arguição podem aparecer nas provas.

\section{Caracterização da pesquisa}

O trabalho emprega uma abordagem qualitativa (SAMPIERI; COLLADO; LUCIO, 2013, p. 376). Entende-se a mesma como um tipo de pesquisa que visa "compreender e aprofundar os fenômenos, que são explorados a partir da perspectiva dos participantes em um ambiente natural e em relação ao contexto". O tipo de pesquisa empregado foi o estudo de caso, visto objetivar-se neste estudo compreender uma singularidade, a concepção de alunos da $3^{\circ}$ série do Ensino Médio do Colégio Estadual Francisco Modesto da Silva. 
Acerca da coleta de dados, empregou-se para a mesma o questionário (OLIVEIRA, 2012), composto por questões discursivas e objetivas. A análise de dados deste trabalho se deu mediante o confronto dos dados obtidos via questionário com os referencias teóricos pertinentes à questão.

\section{Resultados e discussão}

Mediante os dados apresentados foi possível perceber que 91,37\% dos alunos afirmaram ter ouvido falar sobre tráfico de animais, sendo que somente a minoria (8,63\%) disse não ter conhecimento sobre o assunto. Os primeiros apontaram que a temática Ihes foi apresentada via jornais, revistas, televisão e internet, respalda-se neste ponto que a escola não foi mencionada.

Quanto à percepção sobre o que vem a ser o tráfico de animais, o alunado em maioria (97\%) aponta que o mesmo é uma "maneira cruel de maus tratos aos animais silvestres", fazendo menção a retirada desses seres do seu habitat natural. Citaram também a manutenção do animal em cativeiro onde os mesmos são privados de liberdade. Alguns alunos relataram ainda que, já viram muitas pessoas criando animais silvestres e outros ainda (3\%) alegaram que já tiveram ou ainda têm animais silvestres como animal de estimação. Pelo fato dos animais silvestres serem considerados exóticos, acabam tendo uma atenção maior para as pessoas que pretende criar um animal "diferente" (ABRAMSON; SPEER; TROMPSEN, 1995). O último fator pode ser justificado pelo grande contato destes alunos com o ambiente rural, já que a economia da cidade onde foi realizado o estudo é baseada principalmente em atividades agropastoris, com muitos discentes vivendo no campo e tendo contato direto com a fauna silvestre.

Seguindo, questionamos aos alunos: Você já teve ou viu animais silvestres sendo criado como animal de estimação?As respostas estão organizadas na figura 2.

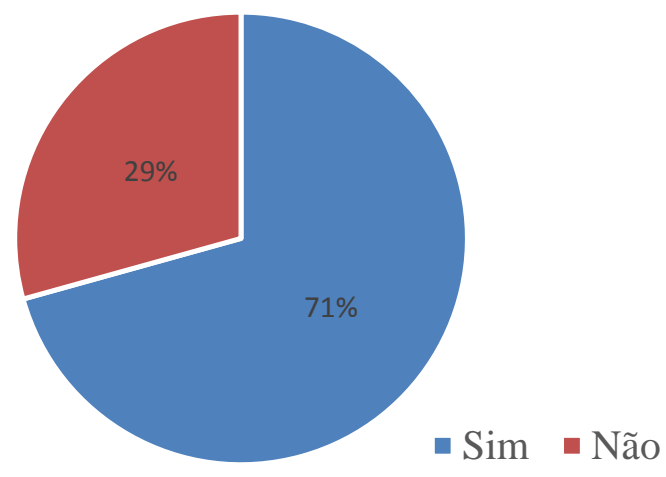

Figura 2. Porcentagem de alunos que já tiveram (ou viram) animais silvestres sendo criados em cativeiros (Fonte: o autor).

Uma parte considerável dos alunos 71\% (Figura 2), responderam que sim, que já criaram e que já viram animais silvestres sendo criados em cativeiro, por vizinhos, amigos e parentes, outros argüiram que sim, mas apenas em televisão, pelos noticiários, e uma minoria de $29 \%$ disseram, não ter visto ou mesmo ter conhecimento sobre o assunto. 0 brasileiro tem uma grande atração por animais silvestres, pois eles são considerados exóticos (SANTOS, 1985), um exemplo são os Paitacídeos, além de sua beleza, tem à 
habilidade de imitar a voz humana (ABRAMSON; SPEER; TROMPSEN, 1995). Vejamos algumas respostas:

Aluno -1 "sim, uma vizinha minha tinha uma arara e uma outra conhecida tinha um mico".

Aluno - 2 "já tive um macaco prego quando morei em fazenda".

Aluno - 3 "já vi em televisão, noticiários sobre pessoas com estes hábitos mais nunca tive"

A próxima pergunta foi: Você já ouviu falar sobre tráfico de animais? O que você entende sobre este assunto?

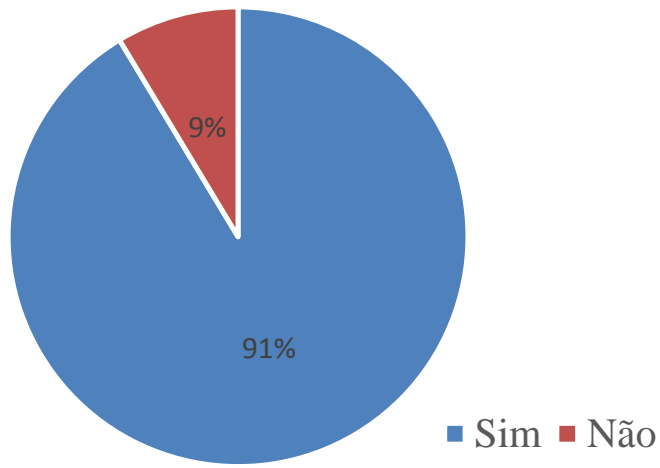

Figura 3: Porcentagem de alunos que já tiveram contato com o assunto (Fonte: o autor).

Outra questão discutida na pesquisa se refere ao contato dos alunos com a temática Tráfico de Animais. Um total de 91\% dos alunos (Figura 3)disse tem conhecimento sobre o assunto, arguindo que já vivenciaram e já viram em noticiários, já uma porcentagem mínima de $9 \%$ dos alunos disseram não ter conhecimento sobre o tráfico de animais.Exemplifica-se com algumas das respostas a seguir:

Aluno - 1 "sim, é a maneira mais cruel que o ser humano encontrou de capturarem animais silvestres e depois vendê-los. Na maioria dos casos, os animais se encontram em péssimas condições".

Aluno - 2 "sim, tráfico de animais é quando pessoas ilegalmente raptam animais silvestres para vender, animais que são maltratados e vendidos para um meio ilegal sem autorização da lei".

Assim, segundo Zago (2008, p. 32) "o resultado do trabalho demonstra a sensibilização dos alunos frente a tais problemas, e demonstra que esta sensibilização já é consequência do processo de educação ambiental ora em desenvolvimento na Escola, mesmo sem estar presente de forma regular em seu currículo escolar, por iniciativa dos professores de Ciências".

É notório que os alunos detêm certo nível de conhecimento sobre o tráfico de animais, entretanto, poucos sabem dos danos causados a nossa fauna. A questão é perceptível ao constatar que muitos conhecem pessoas que possuem animais silvestres em casa e outros ainda manifestarem ter animais silvestres em cativeiro. Isso aponta também o desconhecimento da legislação vigente, além de demonstrar a necessidade de intervenções na Escola sobre questões de EA.

O Meio Ambiente é um tema transversal, sua abordagem de forma crítica reverbera um processo de reflexão acerca da postura do homem em suas relações sociais, podendo culminar em decisões (BRASIL, 1997), por exemplo, ligada a questão do tráfico de animais. 
Constitui-se, pois em um processo de tomada de consciência do sujeito em relação ao seu modo de se relacionar com o Meio Ambiente.

Nesse sentido, respalda-se aqui o papel da formação inicial, pois se advoga em favor de um trabalho com a EA crítica no bojo da Educação Básica, e ainda em outros espaços não formais como museus, a mesma deve ser parte destes cursos, objetivando colocar o futuro professor em contato com essas discussões para quando do seu exercício profissional o mesmo consiga abarcar estas dimensões (OLIVEIRA-NETO et al., 2015). É, assim como coloca Trivelato \& Silva (2011) defender uma forma de pensar a natureza, levando em conta como cada civilização interagia com a mesma, bem como definiam representações sobre ela.

\section{Conclusão}

Os resultados demonstram que o grupo pesquisado parece compreender de forma razoável o que vem a ser o tráfico de animais. Contudo, foi possível notar que, mesmo conhecendo a ilegalidade e também as injúrias causadas pelo tráfico, uma parcela de alunos mantém animais silvestres em cativeiro. Nesse ponto, ressalta-se a necessidade de que a escola volte seu olhar para a EA, a fim de sensibilizar a população, por exemplo, sobre a importância de se evitar condutas que fomentem o tráfico de animais.

Assim, intervenções pedagógicas nas escolas, visando à educação e conscientização ambiental é de extrema importância, para que se possam construir conhecimentos científicos sobre o meio ambiente, visando à participação de todos os cidadãos na preservação dos recursos naturais. Nesse sentido, deve-se buscar romper com a visão de EA que dicotomiza homem e natureza, aborcando as prática educativas no que concerne a essa temática por uma concepção crítica de escola, educação, ensino-aprendizagem, professor e aluno.

\section{Referências}

ABRAMSON, J; SPEER, B. L.; THOMPEN, J. B. The large macaws: their care, breeding and conservation. In: The large macaws, Fort Bragg, California, Raintree Publications, 1995. p.7993

ABREU, R. L. Microrregião de Montes Claros de Goiás. 2006. 1 fotografia. Disponível em:<http://pt.wikipedia.org/wiki/Montes_Claros_de_Goi\%C3\%A1s\#mediaviewer/File:Goias_ Municip_MontesClarosdeGoias.svg>. Acessado em: 01 set 2014.

BRANCO, A. M.; RIBEIRO, H. Descentralização da gestão e manejo da fauna silvestre: o caso da divisão técnica de medicina veterinária e manejo da fauna silvestre do município de São Paulo, Revista INTERFACEHS, v.6, n.1, 2011, p.20-38.

BRASIL. Ministério da Agricultura. Lei no 5.197, de 3 de janeiro de 1967. Dispõe sobre a proteção à fauna e dá outras providências. Brasília, 1967.

BRASIL. Ministério do Meio Ambiente. Instrução Normativa nº 003, de 26 de maio de 2003. Lista Nacional das espécies da fauna brasileira ameaçadas de extinção. Brasília, 2003. 
BRASIL. Ministério do Meio Ambiente. Instituto Brasileiro do Meio Ambiente e dos Recursos Naturais Renováveis (IBAMA). Histórico de apreensões de animais silvestres encaminhados aos CETAS. Brasília, 2014.

DAL'AVA, F. A Evolução da Legislação Brasileira de Proteção à Fauna. In: RENCTAS. Vida à venda. Brasília: VGArte, 2003.

GIRON, G. R.Políticas Públicas, Educação e Neoliberalismo: o que isso tem a ver com cidadania. Revista de Educação PUC-Campinas, Campinas, n. 24, p. 17-26, 2008.

KRASILCHIK, M. Prática de ensino de biologia. São Paulo: Editora da Universidade de São Paulo, 2004.

LOREIRO, C. F. B. Educação ambiental e "teorias críticas". In: GUIMARÃES, M. (Org.). Caminhos da educação ambiental: da forma à ação. Campinas: Papirus, 2006.

MALAFAIA, G.; BÁRBARA, V. F.; RODRIGUES, A. S. L. Análise das concepções e opiniões de discentes sobre o ensino da biologia. Revista Eletrônica de Educação, v. 4 .n. 2, 2010.

OLIVEIRA, M. M. Como fazer pesquisa qualitativa. $4^{\circ}$ ed. Petrópolis, RJ: Vozes, 2012.

OLIVEIRA-NETO, J. F. O.; MOURA, S. F.; SHUVARTZ, M.; OLIVEIRA, L. G. Refletindo a prática da educação ambiental no PIBID-Biologia da UEG, Iporá, Goiás. Enciclopédia biosfera, v. 11, n. 20, p. 726-734, 2015.

QUINTÃO, M. R.; SABINO, C. V. S.; SABINO, G. S. Apresentação e análise de uma metodologia alternativa para trabalhar a resolução de questões de ecologia do Enem. In: Anais do VIII Encontro Nacional de Pesquisa em Educação em Ciências, Campinas, 2011.

RENCTAS, Rede Nacional Contra o Tráfico de Animais Silvestres. Animais Silvestres: vidas á venda. $2^{a}$ ed. Brasília-DF: Dupligráfica, 2003.

RENCTAS. Rede Nacional de Combate ao Tráfico de Animais Silvestres. $1^{\circ}$ Relatório Nacional Sobre o Tráfico de Fauna Silvestre. 2001. 105 p.

SAAB, J. J.Tráfico ilícito de animais silvestres: a resposta penal segundo a lei 9.605/98. 2006. Disponível em: <http://site.unitau.br/scripts/prppg/humanas/download/Humanas\%202006\% 201/Pdf/5\%BA\%20art..pdf>. Acessado em: 19 de julho de 2014.

SAMPIERI, R. H.; COLLADO, C. F.; LUCIO, M. P. B. Metodologia de pesquisa. $5^{a}$ ed. Porto Alegre: Editora Penso, 2013.

SANTOS, E. Amador de pássaros. Belo Horizonte: Itatiais, 1985.

SICK, H. Ornitologia Brasileira: uma introdução. 3a ed. Brasília: Editora UnB, 1988.

TEIXEIRA, L. A.; AGUDO, M. M.; TALAMONI, J. L. B. Análise do processo participativo em projetos ambientais desenvolvidos em um bairro de Bauru/SP. Revista de Educação em Ciências e Matemática, v. 12, n. 23, p. 71-84, 2015.

TRAVASSOS, E. G.. A educação ambiental nos currículos: dificuldades e desafios. Revista de Biologia e Ciências da Terra, v. 1, n. 2, 2001.

TRIVELATO, S. F.; SILVA, R. L. F. Ensino de Ciências. São Paulo: Cengage Learning, 2011.

ZAGO, D. C. Animais da Fauna Silvestre mantidos como animais de estimação. 2008. 39 p. Monografia (Especialização em Educação Ambiental), Universidade Federal de Santa Maria (UFSM), Centro de Ciências Rurais, 2008. 